\title{
The knowledge of coordination for supply chain integration
}

The knowledge of coordination

\author{
Togar M. Simatupang, Alan C. Wright and \\ Ramaswami Sridharan \\ Institute of Information Sciences and Technology, \\ Massey University, Palmerston North, New Zealand
}

Keywords Coordination, Supply chain management, Logistics, Information exchange

Abstract Increasing competition due to market globalisation, product diversity and technological breakthroughs stimulates independent firms to collaborate in a supply chain that allows them to gain mutual benefits. This requires the collective know-how of the coordination mode, including the ability to synchronise interdependent processes, to integrate information systems and to cope with distributed learning. However, research into coordination has paid little attention to acknowledging different modes of coordination. This study promotes the notion of mutuality and the focus of coordination in order to establish a comprehensive taxonomy of coordination modes. Four different modes of coordination have been identified: logistics synchronisation, information sharing, incentive alignment, and collective learning. The knowledge of coordination is then proposed as an explicit understanding about key drivers of coordination modes that have positive impacts on supply chain performance. This paper also presents a research agenda.

\section{Introduction}

A firm needs to develop effective coordination within and beyond its boundaries in order to maximise the potential for converting competitive advantage into profitability (Dyer and Singh, 1998). Coordinating the rate of order fulfilment to match actual consumption is successful from the customer's point of view, if it results in satisfying a customer's delivery date and lowers logistics costs. WalMart, for instance, shares point-of-sales data - including sales and stocking data - with its key suppliers (Simchi-Levi et al., 1999). Tracking daily sales enables the suppliers to differentiate popular from slow-moving items and to respond quickly either to replenish or to discontinue the items in retail stores. Tight coordination between Wal-Mart and its key suppliers dramatically increases product availability and reduces inventory costs.

Coordination among independent firms, such as raw-material suppliers, manufacturers, distributors, third-party logistics providers and retailers, is the key to attaining the flexibility necessary to enable them to progressively improve logistics processes in response to rapidly changing market conditions. Poor coordination among the chain members can cause dysfunctional operational performance. Some of the negative consequences of poor coordination include higher inventory costs, longer delivery times, higher transportation costs, higher levels of loss and damage, and lowered customer service (Lee et al., 1997). Since

The authors wish to thank Dr Majed Al-Mashari, the Editor, and anonymous reviewers for their constructive suggestions that have substantially improved the appearance of this article.

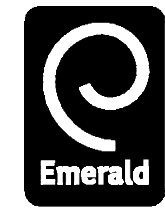

Business Process Management Journal, Vol. 8 No. 3, 2002, pp. 289-308. (C) MCB UP Limited, 1463-7154 DOI $10.1108 / 1463715021042898$ 
BPMJ

8,3

290 changes that occur in any one of the chain members are likely to affect the performance of the others, coordination is useful for managing interdependent logistics activities in order to mitigate demand variability and unnecessary inventory. A process of planning, executing and controlling the interdependencies of activities carried out by different supply chain members or business units in order to create value for the end customer is known as supply chain management (Lambert et al., 1998).

Given the critical importance of coordination, few researchers have appeared to develop and test the concept of coordination in the supply chain. Senge (1990) popularised systems thinking that can be used to understand the reality of logistics and coordinate the chain members in order to create collective knowledge. Konijnendijk (1994) examined the coordination process at tactical and operational levels about product specification, volume, mix and lead-times between sales and manufacturing in engineer-to-order (ETO) companies. Stank et al. (1999) studied inter-firm coordination processes characterised by effective communication, information exchange, partnering and performance monitoring in food industry supply chains. Lee et al. (1997) suggested channel coordination, operational efficiency and information sharing to improve the overall supply chain performance. Current research often emphasises a single coordination mode as the act of managing specific objects such as interdependent processes, information and knowledge. Little attention has been given to exposing different coordination modes and their interactions. The exception was Lee (2000), who provided an interesting concept of supply chain integration that consists of information sharing, logistics coordination and organisational relationship linkage. Pyke et al. (2000) shared this concept and tested it in an empirical study. However, Lee (2000) considered only the coordination mode due to process realignment and said nothing about combining different modes of coordination. Unlike Lee's approach, this study considers information sharing as a special type of coordination mode.

The objective of this study is to formulate a framework of the knowledge of coordination that unifies the different modes of coordination required to integrate the supply chain processes of different partners in order to achieve chain profitability. It is argued that, if the supply chain members want to maintain their competitive edge by innovation throughout the supply chain network, then the creation of shared context for improvement is essential. The question is how to achieve the best fit among the supply chain partners, so that the tasks of different players are completed in a manner consistent with the mutual goal, because supply chain performance depends on how well all members work together and not on how well each member performs separately.

The notions of mutuality and focus of coordination are adopted to build a taxonomy of different coordination modes. The idea of mutuality refers to combining efforts among independent firms (MacNeil, 1980). Mutuality consists of complementarity and coherency of activities among the chain members, whereas the focus is on emphasising operational and organisational 
linkages. Four coordination modes are identified in the taxonomy: logistics synchronisation, information sharing, incentive alignment and collective learning. Each coordination mode has typical problems that require specific resolutions. Integrating the acts of different players to achieve the common goal requires knowledge of coordination. Knowledge of coordination consists of an explicit understanding about key drivers of coordination modes that have significant impacts on supply chain performance.

The paper begins by presenting a revisited taxonomy of coordination modes. The following sections briefly discuss each coordination mode. Next, a special section is devoted to demonstrating the idea of the knowledge of coordination in supply chain management. A discussion section provides general comments and implication for further research. The concluding section summarises the important ideas of the paper.

\section{A taxonomy of coordination modes}

A symbiotic relationship becomes important to facilitate networking among divisions within a firm, or between firms in a supply chain. The main concern of supply chain management is how to coordinate the independent players to work together as a whole to pursue the common goal of chain profitability in changing market conditions. Generally, Malone and Crowston (1994) define coordination as the act of managing interdependencies between activities performed to achieve a goal. In the supply chain context, coordination can be viewed as an act of properly combining (relating, harmonising, adjusting, aligning) a number of objects (actions, objectives, decisions, information, knowledge, funds) for the achievement of the chain goal. Since the nature of an object of coordination varies, a separate coordination mode is required to manage a specific object. Although the chain members implicitly apply different coordination modes to assist one another to manage processes, capabilities and information in response to market uncertainty, little attention has been paid to distinguishing and unifying them. This section presents a comprehensive taxonomy of coordination that attempts to differentiate and classify different coordination modes in order to gain a better clarification.

A taxonomy of coordination refers to the act of classifying different coordination modes under one roof. Presenting different coordination modes under one roof makes it possible to understand why scholars and practitioners work with different objects and concentrate upon different modes of coordination. The proposed taxonomy looks at two dimensions: the mutuality of coordination and the focus of coordination (see Figure 1). The following paragraphs discuss the logics underlying the proposed taxonomy.

The mutuality of coordination can be defined as the underlying values of responsibility among partners with a strong emphasis on sustaining relationship in order to build effective goal attainment. The literature of social contract has recognised that any relationship among business partners must contribute to a climate of mutuality (see Campbell (1997) for a theoretical framework of mutuality in business relationships). MacNeil (1980) argues that
The knowledge of coordination 
BPMJ

8,3

292

some degree of mutuality is important to strengthen the closeness of the relationship that results in better-coordinated activities among trading partners. The mutuality norm suggests that each partner contributes to significant values and is entitled to an equitable distribution of exchange outcomes. The collective responsibility is meaningful, if the partners share mutual accountability in attaining a better performance. For example, the retailer and the manufacturer share joint responsibility to implement the initiative of quick response as a strategy to cut lead-times and increase the speed of product introduction to the market. Besides the joint responsibility of creating value, both partners share the mutual savings, which result from quick response such as lowered logistics costs and increased profit.

The literature of systems thinking also advocates that the mutuality among chain members provides the opportunity to focus on operational improvement that has a dramatic impact on the overall chain performance (Senge, 1990; Goldratt, 1994). Coordination will fail, where perceptions of mutuality for other members and commitments to the system (holism) are absent (Lee et al., 1997; Checkland, 1999). The mutuality of coordination is required to enable chain members to share explicit understandings about the overall picture of end-toend supply chain processes and the focus of improvement (Goldratt, 1994). For example, the visibility of demand information helps the chain members to eliminate unnecessary inventory and deliver products and services according to the actual demand (Simchi-Levi et al., 1999).

The mutuality of coordination can be divided into two main dimensions, namely complementarity of processes and coherency of understanding. Complementarity refers to how the chain members collectively manage interdependencies between logistics activities to create value. Interdependence is the degree to which one process depends on the other to achieve the overall value creation processes. Managing logistics processes along the supply chain and removing economic barriers such as incentive misalignment are the concerns of complementarity. Milgrom and Roberts (1990) initiate the concept of complementarity between interdependent activities and modern manufacturing. They argue that modern manufacturing does not involve small adjustments made independently but rather substantial and coordinated changes in the overall business processes from material procurement to product delivery. Complementarities among those activities lead to increases in mutual values such as increased sales and lowered logistics costs that can be shared by the participating members. Similarly, complementarity of the

Figure 1.

A taxonomy of coordination modes in a supply chain

\begin{tabular}{|c|c|c|c|}
\hline & \multicolumn{2}{|c|}{ Mutuality of Coordination } \\
\hline & & Complementarity & Coherency \\
\hline \multirow{2}{*}{$\begin{array}{l}\text { Focus of } \\
\text { Coordination }\end{array}$} & $\begin{array}{l}\text { Operational } \\
\text { linkages }\end{array}$ & $\begin{array}{l}\text { Logistics Synchronisation } \\
\text { (Object: products/services } \\
\text { and logistics processes) }\end{array}$ & $\begin{array}{l}\text { Information Sharing } \\
\text { (Object: information) }\end{array}$ \\
\hline & $\begin{array}{l}\text { Onganisational } \\
\text { linkages }\end{array}$ & $\begin{array}{l}\text { Incentive Alignment } \\
\text { (Object: benefits and } \\
\text { risks) }\end{array}$ & $\begin{array}{l}\text { Collective Leaming } \\
\text { (Object knowledge } \\
\text { and capability) }\end{array}$ \\
\hline
\end{tabular}


logistics processes across the supply chain leads to substantial benefit for all members. When chain members synchronise decision making about value creation to ensure a seamless flow of goods and services and coordinate the benefit sharing associated with logistics improvement, they are likely to shape complementarity.

Coherency refers to the degree of consistency of reasoning across organisational borders through diffusing common understanding. To meet the requirements for coherency, the chain members need to share information and knowledge that can be used to make sense of the process interdependencies and to manage uncertainties along the supply chain. Lissack and Roos (2001) verify the fact that organisations must find ways to make sense about their identity in a turbulent environment in order to build a coherent viewpoint and actions. Coherency can be seen as the alignment of context, viewpoint, purpose and actions to attain the shared goal through information sharing and collective learning. For example, when knowledge of market and technology is diffused in meaningful ways, the chain members are able to coordinate the product development processes to launch innovative products on time.

The second dimension is the focus of coordination on either operational or organisational linkages. Linkages exist when activities taken by one chain member affect activities or outputs of another chain member. Therefore, linkages are the interfaces between firms where chain members need to coordinate their joint decisions. Operational linkages focus on the integration of interdependent processes and information flows that provide ways for partners to carry out logistics planning and day-to-day transactions. Recognising operational linkages allows the chain members to contribute to, and become involved in, the operational decision making. Organisational linkages consist of interconnected actors who perceive and argue about their own interests in carrying out collective action. Appreciating organisational linkages allows them to understand partnership activities and bargaining realities. Both of these linkages provide the groundwork for successful coordination.

As shown in Figure 1, four coordination modes can be identified based on the two dimensions of coordination:

(1) logistics synchronisation;

(2) information sharing;

(3) incentive alignment; and

(4) collective learning.

Each coordination mode has different contexts and emphasises different cognitive processes. The coordination of logistics synchronisation is responsible for ensuring alignment between logistics process activities to deliver products and services to fulfil customer needs and wants (Fisher, 1997). The coordination of information sharing attempts to realise the coherency of information, while actors cooperate with one another and follow rules of diffusing information across borders (Lee, 2000). Incentive alignment attempts
The knowledge of coordination 
BPMJ

8,3

294

to provide various mechanisms to distribute benefits and risks associated with logistics functions to motivate independent actors in order to achieve supply chain profitability (Lee, 2000; Simatupang and Sridharan, 2002). The coordination of collective learning deals with how to tackle the coherency problem of initiation and diffusion of knowledge across borders (Senge, 1990; Sawhney and Prandelli, 2000). The following sections discuss strategies of each coordination mode and expose insights from real world applications.

\section{Logistics synchronisation}

Logistics synchronisation means recognising and concerting improvement initiatives that significantly contribute to value creation in the acquisition, consumption and disposition of products and services in today's rapidly changing markets. This typical coordination refers to the market mediation function of a supply chain that aims to match the variety of products reaching the marketplace with customer needs and wants (Fisher, 1997). Understanding customer demand and concerting inventory management, facility and transportation between partners help to realise dramatic improvements in the forms of rapid response to customer requirements, lowered inventory costs, improved product availability, minimum obsolescence and minimum variance of any unexpected events such as forecasting errors and delays that disrupt chain performance (Lambert et al., 1998).

Logistics synchronisation also assists participating members to resolve role conflict, so each member can perform specific tasks and assume certain responsibility to ensure the attainment of chain profitability. The real challenges include focusing on core activities that provide real value to the customer, and subordinating other supporting activities to ensure the value creation process. Analysing the value creation process across the supply chain can provide a road-map for strategic initiatives that clarify specific roles for each participating member. Govindarajan and Gupta (2001) suggest three interrelated areas to ensure logistics synchronisation:

(1) customer definition;

(2) customer value identification; and

(3) value creation process design.

If the chain members can dramatically redefine the customer base, reinvent the concept of customer value, and redesign the end-to-end value chain architecture, then they are likely to create competitive advantage from the customer's viewpoint.

Several strategies of logistics synchronisation have been developed based on the principles of logistics management - such as collaborative logistics processes, operational flexibility, logistics postponement and collaborative transportation. The collaborative logistics processes refer to joint decision making such as assortment planning, joint forecasting, joint inventory management and replenishment (Simchi-Levi et al., 1999). Operational 
flexibility aims to provide various demand response strategies by considering supply capacity such as make-to-forecast, locate-to-order, amend-to-order and build-to-order (BTO) (Holweg and Pil, 2001). Logistics postponement refers to delaying product differentiation to the latest possible time until customer orders are received (van Hoek, 2001). Collaborative transportation attempts to employ the third-party logistics providers to accomplish in-bound and outbound logistics. Direct shipping, warehousing, and cross-docking are three distinct out-bound strategies to deliver goods to end customers (Simchi-Levi et al., 1999).

Employing those strategies often depends on specific industry characteristics. For example, the fashion industry often faces high demand uncertainty, short selling period, long procurement lead-time, high variety of customer preferences and mark-down risk of product obsolescence. Collaborative forecasting, inventory management and rapid response fit the requirements of the apparel industry (Fisher, 1997).

Benetton, Nike and Dell are examples from the real world that show how supply chains are synchronised to create customer value. Benetton applies the postponement strategy to produce a large variety of coloured garments in a short selling season by developing a production process in which the garment is dyed after being knitted (Dapiran, 1992). Traditionally, thread was dyed and then the garment was knitted. The problem with this sequence is that the knitting is slow and thereby requires a high stock of finished garments to fulfil standard customer service. Benetton uses postponement to make better decisions about colours that reflect the market trend. Since the cost of the production process with postponement is more expensive, Benetton still operates the traditional process to produce items with low demand uncertainty. Nike has reaped profitability by concentrating on its strengths in designing and marketing high-tech and fashionable footwear for sports and fitness (Tully, 1993). Nike established one small manufacturer that makes some sneaker parts. Other supporting activities such as footwear production are subcontracted to suppliers in Taiwan, South Korea and other Asian countries. Synchronising its speciality and its suppliers' capabilities allows Nike to build-in flexibility to keep up with the changing tastes of customers.

Dell prospers by focusing on two aspects of the computer business: direct sales and build-to-order production (Magretta, 1998). It sells personal computers directly to customers and thereby eliminates the reseller's mark-up and the costs and risks of large inventories of finished products. Build-to-order production means that a product is customised and manufactured according to specific customer request. Dell owns no plants but leases two small factories to assemble computers from outsourced parts. Internet-based technology is used for just-in-time ordering and to share daily schedules with the suppliers. The suppliers utilise shared data to plan and adjust procurement and production in order to deliver parts and components to the factory only when they are needed for assembly. Dell's strategies of direct sales and build-to-order production have proven successful in minimising inventory and bringing new products to
The knowledge of coordination

\section{5}

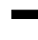


BPMJ

8,3

296

market quickly, enabling it to increase market share and achieve high returns on investment.

\section{Information sharing}

The coordination of information sharing attempts to make relevant, accurate and timely information available to the decision-makers (Lee, 2000). Chain members often have different private information, which is often not shared with others - thus asymmetric information is inherent in supply chains (Simatupang and Sridharan, 2002). For example, the retailer has better projected customer demand compared with the manufacturer (Lee et al., 1997). The manufacturer has better information about products, delivery lead-times and production capacity than the retailer. Traditional communication between the manufacturer and the retailer is made through periodic ordering in large batches. This ordering behaviour distorts original demand information, because demand variance becomes larger, as order data percolate to the upstream members. The idea is, then, to share demand information with the upstream members. The visibility of demand data and inventory at the point of sales allows the upstream members to update forecasts and ensure continuous replenishment of the products.

Information technology (IT) such as the Internet, intranet, software application packages and decision support systems can be applied to facilitate information sharing with customers and partners, and optimisation of supply chain performance. IT applications for customer orientation include informational facility (i.e. online information about custom and standard products, a comprehensive, frequently asked questions section, contact person, return policy, etc.) and transactional facility (e.g. online order submission, order modification, order notification, order tracking, security of online payment and technical assistance). IT applications for partner orientation enable participating members to gain visibility about customer demand (e.g. customer profiles, products, prices, locations, quantity and demand patterns), resource planning (e.g. forecasting, shipping schedules, inventory, capacity, location, lead-times and products), and contract status such as price, automatic ordering, order-status tracking, invoicing, auction, incentive score-board and electronic payment. This level of information sharing acts as the glue that integrates all chain members. IT, for instance, enables chain members to monitor the order fulfilment process from manufacturing, shipping and order receiving. IT applications for optimisation provide analysis of supply chain status and various intelligent recommendations for operational and tactical decisions (Simchi-Levi et al., 1999).

The coordination of collection, processing and dissemination of information among the chain members must be accompanied by the readiness of the chain members to use shared information in the execution of logistics tasks that contribute to operational and financial performance. For instance, the manufacturer needs to reengineer its operation for late-phase differentiation to take advantage of receiving real-time customer orders (Simchi-Levi et al., 1999). 
The reason is that information sharing provides more mutual gains from the replacement of physical costs with information costs and less from reductions of exchange costs of information (Lee and Whang, 2001). The physical costs include the expenses associated with the conversion, transportation and storage of goods from material sources to end customers. The movement of physical goods also runs various risks such as inventory costs, obsolescence, damage, loss and spoilage. Therefore, the use of information sharing to substitute physical processes creates more benefits. To achieve success, the chain members need to have logistics synchronisation that consists of formal processes to improve customer value and profitability in response to shared information.

Several examples from the real world testify that information sharing provides necessary visibility of the global scope in order to enable better decisions to be made in order to maximise the total profit. Wal-Mart considers the broader scope - including supplier information - when trying to set the optimal inventory levels. The firm requires information that includes demand patterns, inventory-carrying costs, ordering costs, costs of stocking-out, and the upstream suppliers' lead-times and variability. Check-out scanners are used to capture detailed data of demand patterns and inventory-on-hand at the points of sale. Collecting detailed data of demand patterns, margins and supplier information assists Wal-Mart to determine the optimal stocking quantity at each of its stores and to decide when to reorder products from the suppliers. Dell substitutes information for inventory and delivers a finished product only when it has a real demand from an end customer (Schonfeld, 1998). Dell provides visibility of customer orders, inventory levels and replenishment needs regularly to its component suppliers. Those suppliers are able to see what parts Dell needs today and what parts will be needed in the coming week. All chain members reap the benefits of information sharing. The suppliers can increase the accuracy of their forecasts, cut shipping lead-times and reduce inventory on-hand. Dell is able to create excellent order-to-delivery time for its direct customers.

Benetton electronically receives orders and sales information from hundreds of company agents located around the world (Dapiran, 1992; Camuffo et al., 2001). By tying its logistics and manufacturing systems in with its suppliers and company agents, Benetton can achieve both the best cycle times in the industry and near-perfect customer service levels. It has also reduced costs from lost sales and mark-downs. Levi Strauss, another fashion firm, also capitalises on information sharing and computerised fabric cutting to customise a variety of jeans for different customers (Schonfeld, 1998). With the increase in customisation, Levi Strauss can charge premium prices for personally fitted jeans.

\section{Incentive alignment}

Incentives define how decision-makers are to be rewarded or penalised for the decisions they make. Existing incentives influence individual member
The knowledge of coordination 
BPMJ

8,3

298

behaviour and its interaction with other partners. Conflict of interest is likely to occur when the existing incentives lead to actions that maximise personal gain but often reduce the total profitability (Clemons and Row, 1993). Traditional incentive schemes are often based on local costs and short-term concessions that attempt to fill the gap in inventory between chain members. The perverse incentives, such as local inventory cost, transportation cost and lot-size-based quantity discounts, often do not support the value creation process of improving customer services, because those incentives are tied to the action of reducing the internal costs of one stage of the supply chain. This local optimisation often sacrifices the total profit (Simchi-Levi et al., 1999). For example, the manufacturer rewards the retailer based on the number of units or lot-size purchased over a set period. The retailer takes advantage of this quantity discount by loading up inventory. Then it sells the product later at the regular price (forward-buying) or sells it to other retailers for profit (diversion) (Clemons and Row, 1993).

One way to resolve such a conflict of interests is to offer incentive schemes linked to the global performance that reflects both value creation for the customers and profitability (Simatupang and Sridharan, 2002). This coordination mode is called incentive alignment that induces the partner behaviour, which is consistent with customer focus and total profit (Lee, 2000). Firms that share complementarity of business process will attempt to resolve incentive misalignment in mutually satisfying ways based on a relational contract especially to manage risks associated with demand uncertainty. A relational contract specifies parameters such as price, quantity, time and quality that guide how a buyer places orders and a seller fulfils orders. Examples come in many forms including relationship pricing (i.e. volumebased quantity discounts, functional allowances and promotional allowances); a subsidy for products returned, consignment and price protection; capacity reservation such as back-up agreements and quantity flexibility contracts; tying bonuses to desirable performance, such as minimising forecasting errors, sales-through, customer service, speed of delivery and product availability; stabilising the transfer price, such as an every-day-low-price (EDLP) and everyday-low-cost (EDLC), and gain-sharing schemes (Stern et al., 1996; Simchi-Levi et al., 1999) .

Examples from the practical world suggest that incentive alignment can motivate chain members to satisfy customer needs and increase their total profit. Benetton uses quantity flexibility contracts that allow its retailers to change the order quantity of the coloured kit garments after observing early demand (Dapiran, 1992). The retailers are required to commit a number of units several months before the start of the season. They can increase and lower the order quantity for each colour by a certain percentage, but not the aggregate quantity of the product, because aggregate forecasts are more accurate compared with forecasts for individual colours. All parties reap benefits from the quantity flexibility contract. As the demand for fashion apparel is often uncertain several months before the selling season, the retailers can take 
advantage of updated demand forecasts and adjust buying decisions closer to, or during, the selling season. Order commitments from the retailers allow Benetton to apply tailored sourcing that substantially reduces costs. Benetton subcontracts the committed portions with low demand uncertainty to low cost sources that have long lead-times of several months. When the updated demand forecast exceeds expectation, Benetton can ensure product availability at the retailer stores by subcontracting the reordering portion to flexible sources that have short lead-times of several days.

Dell encourages its parts suppliers to deliver in small batches to increase inventory speed in compensating with higher order commitment and cash receivables (Magretta, 1998). Quantum Chemical Company uses gain-sharing contracts with its third-party logistics providers (Lambert et al., 1998). Instead of using a fixed management fee or a cost-plus basis, Quantum offers an incentive scheme tied to surpassing expectations in order accuracy, on-time delivery, inventory accuracy, eliminating customer complaints and reporting timeliness. This scheme motivates the logistics providers to guarantee service and cost savings. Suppliers of computer hardware offer a subsidy on price protection, mid-life returns and end-of-life returns to motivate their resellers to maintain a high level of product availability (Campbell and Pereira, 1998). This subsidy is given to compensate for the sharp decline in the retail price and technology over the life cycle of the computer hardware due to rapid innovation and new product introductions.

\section{Collective learning}

The coordination of collective learning deals with how to tackle the coherency problem of initiation and diffusion of knowledge across organisational borders (Sawhney and Prandelli, 2000). Special emphasis is placed on practical learning from one another for understanding and creating tacit capability in implementing particular logistics improvement initiatives. Mastering tacit capability involves intensive dialogue, experimentation and discussion of data, information and knowledge to attain collective sense making (Senge, 1990). The objective of the coordination of collective learning is to extend each partner's capability that is useful for accomplishing ongoing improvement.

The coordination of collective learning not only consists of analysis and synthesis of ongoing improvement, but also includes how to ensure the buy-in of key collaborators in the implementation phase. The key collaborators must embrace the necessary changes to implement the solution. The initiator of a breakthrough solution should be able to overcome the layers of resistance to change that consist of disagreement about the nature of the problem, disagreement about the direction of the solution, disagreement as to whether the solution will result in the desired effects that are necessary for the organisation, disagreement as to whether or not the solution has disastrous side-effects, disagreement that the solution is viable in the environment, and unverbalised fear (Smith, 2000). This structural approach in achieving buy-in paves the way for creating, adopting and diffusing useful knowledge for
The knowledge of coordination 
BPMJ

8,3

300

building commitment to change. There are various means of transferring knowledge to support this change process, including personal communication (meeting, discussing by telephone, e-mail, etc.), codified communication (reports, drawings, etc.), joint training and apprenticeship.

Several examples from real world application show that collective learning can be used to improve the capabilities of managing the supply chain. Close customer relationships allow Dell to understand and satisfy their needs (Magretta, 1998). Dell segments its customers into categories such as consumer, medium business, large corporate, government and education. With direct contact, it is possible to gather credible data about customer needs and buying trends. Each segment has its own sales, marketing and technical support teams. This method allows Dell to tailor marketing, sales and services strategies to the unique requirements of each of those types of customers. Through collective learning, Dell is able to extend the skill of demand forecasting that guides the design of product and ordering flows from the customers to the suppliers.

Sport Obermeyer, a manufacturer of fashion ski-wear, constantly experiences the risks of demand uncertainty such as stock-outs of popular styles during the selling season and left-over stock of the duds at the end of the season (Fisher, 1997). Accurate response was adopted to coordinate three strategies consisting of reducing uncertainty (e.g. collecting additional data on early sales), avoiding uncertainty by cutting lead-time, and hedging against residual uncertainty such as maintaining buffers of stock. After acquiring the skill of accurate response, Sport Obermeyer was able to improve demand forecast, shorten the procurement lead-time, and discover a means of selecting which styles to make early. This new capability assisted Sport Obermeyer to increase profit and improve product availability. Benetton and its retailers have jointly learned to adopt sophisticated marketing techniques, such as in-store testing and monitoring market trends in styles, sizes and colours to obtain a better understanding of customer preferences and expectations (Camuffo et al., 2001). Benetton uses the skill of capturing customers' last-minute needs to design and offer an appreciated variety of fashion goods to the right customers.

\section{Towards the knowledge of coordination}

The knowledge of coordination is defined as an explicit understanding about key drivers of coordination modes that affect supply chain performance. Key drivers refer to a number of solutions or interventions in a specific coordination mode to improve supply chain performance. For example, key drivers of logistics synchronisation, such as reducing uncertainty, reducing variability and lead time reduction, have dramatic impacts in reducing inventory costs and increasing the level of customer service. The chain members need to articulate their understanding about the principles of coordination modes and make it available to others. This explicit understanding allows them to anticipate subtle interactions and unintended consequences. A web of causeand-effect, for example, can be presented with the use of a rich picture 
(Checkland, 1999), cognitive maps (Eden and Ackermann, 1998), systems thinking (Senge, 1990), and thinking process (Goldratt, 1994). Each method of eliciting and displaying explicit understandings has its own strengths and limitations.

Two related concepts are used to verify the knowledge of coordination in the supply chain: the individual contribution of coordination mode in attaining supply chain integration and the use of the drivers of coordination modes to attain operational excellence. Figure 2 depicts the conceptual framework of the knowledge of coordination used to scrutinise the contribution of each coordination mode in order to achieve an integrated supply chain. The recursive interplay between an integrated supply chain and the four modes of coordination generates four loops of contributions. The first loop consists of the value creation process that is designed to improve both individual and overall supply chain performance through implementing improvement initiatives. Ongoing initiatives offer the focus of improvement that directly impacts on supply chain profitability. Participating firms coordinate both the process and outputs of logistics activity to match supply and demand (Fisher, 1997). An integrated supply chain is expected to result in improved customer service levels, lowered costs and increased sales. In turn, improved performance resulting from coordinated actions augments the level of collaboration to enhance logistics synchronisation.

The second loop is concerned with facilitation that enables participating members to have visibility of customer demand, product movement and performance metrics. Shared information provides visibility enabling consideration of a global scope to make better decisions that optimise supply chain performance. Thus, visibility assists chain members to integrate logistics processes that can be optimised to increase responsiveness to changing market conditions. As visibility intensifies among chain members, it generates the

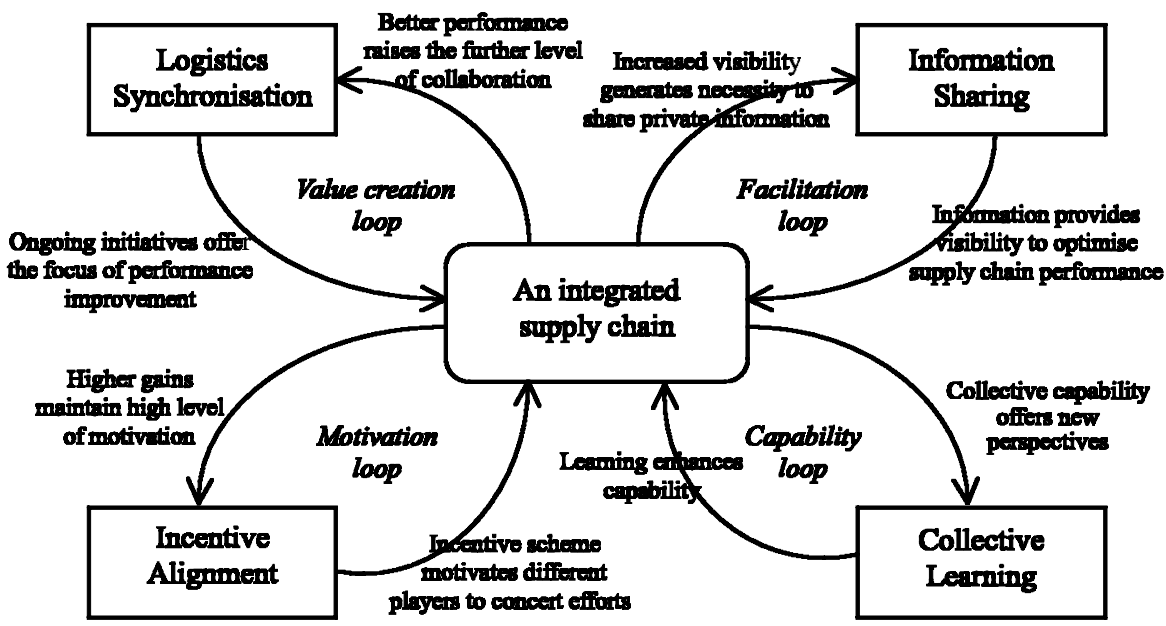

The knowledge of coordination

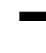


BPMJ

8,3

302

necessity to reveal more accurate and timely private information such as sales data, costs-related data and processes-related data.

Third, an incentive scheme is often offered before the mutual benefits are realised. As shown in the motivation loop of Figure 2, an incentive scheme is designed to motivate the chain members to align decisions and actions with supply chain profitability. A certain level of chain performance is expected to be realised that leads to mutual benefits. Some, or all, of the mutual benefits which result from better coordination can be distributed in more incentives. Higher gains from incentives would influence the behaviour of decision makers to improve chain performance. This process will continue to shape a loop of motivation.

Finally, the capability loop intends both to combine fragmented skills and to enable chain members to acquire new skills from one another. Collective learning can be effective in enhancing capability to carry out improvement initiatives. However, collective learning is a give-and-take proposition. Besides closing its own skill gaps, a partner must contribute unique capabilities to maintain influence in the supply chain. A coordinated supply chain allows participating members to develop collective capability. In turn, this collective capability offers new understanding about market opportunities. As a result of collective learning, trust between parties begins to grow and this leads to an increase in confidence for further innovation of performance improvement.

The knowledge of coordination can be used to expose the interaction of key drivers of coordination modes affecting supply chain performance. A simple cause-and-effect diagram in Figure 3 shows the fact that the drivers of coordination modes lead to the realisation of operational and financial performance. For example, analysis of customer needs may reveal that product availability is highly valued by customers. Thus, improved product availability leads to customer loyalty, which, in turn, leads to increased sales. Once the framework has been applied to understand the interaction of key drivers among the coordination modes and their impacts on supply chain performance, the focus and leverage for productive change can be identified. To illustrate, logistics synchronisation specifies what are the most effective initiatives, who will carry out optimisation, and the measures of success. This coordination mode interacts with other types of coordination modes. The coordination of collective learning uses the contents and context of logistics synchronisation as learning subjects. Logistics synchronisation also determines information needs that guide information sharing and the basis of

Figure 3.

Key drivers of coordination modes leading to supply chain performance

\begin{tabular}{|c|c|c|}
\hline $\begin{array}{l}\text { Key drivers of coordination } \\
\text { modes: } \\
\text { - Logistics Synchronisation } \\
\text { - Information Sharing } \\
\text { - Incentive Alignment } \\
\text { - Collective Leaming }\end{array}$ & $\begin{array}{l}\text { Operational Performance: } \\
\text { - Customer service } \\
\text { - Inventory velocity } \\
\text { - Speed of responsiveness } \\
\text { - Product quality } \\
\text { - Product availability } \\
\text { - Lead-times }\end{array}$ & $\begin{array}{l}\text { Financial Performance: } \\
\text { - Cash conversion time } \\
\text { - Logistics cost } \\
\text { - Net asset returns } \\
\text { - Total inventory days of } \\
\text { supply }\end{array}$ \\
\hline
\end{tabular}


measures for incentive alignment. Similarly, other coordination modes also contribute to the act of logistics synchronisation. Incentive alignment motivates the chain members to optimise the logistics processes by splitting the savings resulting from the coordinated efforts. Collective learning assists chain members to catch up with the capabilities required to create logistics innovations. Information sharing eliminates lack of visibility about product movement and logistics processes. To sum up, an understanding of the interaction of the drivers among coordination modes is important for devising a means of harmonising them in an attempt to attain superior supply chain performance.

The experience of Dell provides an example of how to use the knowledge of coordination to improve supply chain performance (Govindarajan and Gupta, 2001; Holweg and Pil, 2001). Dell coordinates information sharing, incentive alignment and collective learning to focus on direct selling and build-to-order. Direct selling allows Dell to have better understanding about customer needs and wants. This knowledge can be used to improve the accuracy of demand forecasts. Dell also shares demand information and daily schedules with its component suppliers. Its suppliers use this shared information to improve their internal operations, so as to be capable of providing just-in-time delivery. Just-intime delivery significantly reduces the level of unnecessary inventory and increases cash conversion time. Just-in-time production also means delivering more products with the latest technology and customised configuration to end customers. Satisfied customers provide cash receivables and loyalty to Dell. The knowledge of coordination about build-to-order, visibility of demand information, inventory speed, and supplier and customer relationships demonstrates how Dell and its suppliers can reap mutual benefits, such as customer satisfaction, profitability and high market share.

\section{Discussion and future research}

Dealing with interdependency and handling uncertainty are the two most frequent objectives of research that aims to integrate independent players in order to achieve the collective goal. The interesting question is whether phenomena of cognition at the individual level can contribute to strategies at the global level (i.e. a total system). This integration effort requires different modes as means for working together and inviting people from the entire system to participate in collective enquiry. Four types of coordination modes have been identified in this study:

(1) logistics synchronisation;

(2) information sharing;

(3) incentive alignment; and

(4) collective learning.

Each coordination mode has its key drivers used to leverage performance. The knowledge of coordination is proposed as a collective understanding about the
The knowledge of coordination

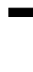


BPMJ

8,3

304

drivers of coordination modes that can be used to improve supply chain profitability.

The contribution of the conceptual framework to the current research is to address the basic challenges of mutuality in supply chain management. The primary challenge is to overcome the risk that supply chain members are not all focused on improvement initiatives. The secondary challenge is to mitigate the risk that individual members do not share their private information in an optimum fashion with their partners. The tertiary challenge deals with alleviating the lack of motivation for individual members to align local decisions with the mutual goal. Furthermore, it is often found that participating members either do not reveal the knowledge they have or they choose to make use of it for their own advantage. The knowledge of coordination is akin to what Kogut and Zander (1992) have called "combinative capacity", that is the ability to generate innovative combinations based on knowledge and capabilities distributed throughout the supply chain network. Thus, the knowledge of coordination offers the opportunity to pave the way to understanding how the relational view is able to create conditions for attaining a common goal among independent parties.

Several key issues of the knowledge of coordination are open areas for future research. An empirical study is required to examine the impact of tying together key drivers of coordination modes on supply chain performance. How to capture arguments and propositions of key managers about main drivers of improvement in a supply chain is a critical issue, because an explicit understanding shows the relationship between collective action, commonly held beliefs and supply chain performance. Illustrating this understanding by way of causal maps creates an opportunity to identify obstacles and devise proper interventions.

An explorative study is necessary to examine the real value of the knowledge of coordination in the practical world. Since the knowledge of coordination in real life is embedded in the mental models of the participants who are involved in the partnership, the case study method seems suitable to elicit excellent practices in the real world implementation (Yin, 1994). Covington (2000) and Akkermans et al. (1999) provide two examples of using the case study method to capture the mental models of decision-makers in the specific supply chain. Covington (2000) conducted a case study on how to resolve supply chain discontent in the apparel industry in order to improve the chain's performance for the good of all involved. Akkermans et al. (1999) elicited mental models from various experts about vicious cycles frustrating the implementation of effective international supply chain management.

Several issues of each coordination mode also call for further exploration. Table I shows several key questions for future research. Empirical study of the value of logistics synchronisation would be useful to identify and focus on the most effective initiatives for value creation. Further research is required to develop coordination methods of matching different segments of customer needs and wants and tailored improvement initiatives. Those coordination 


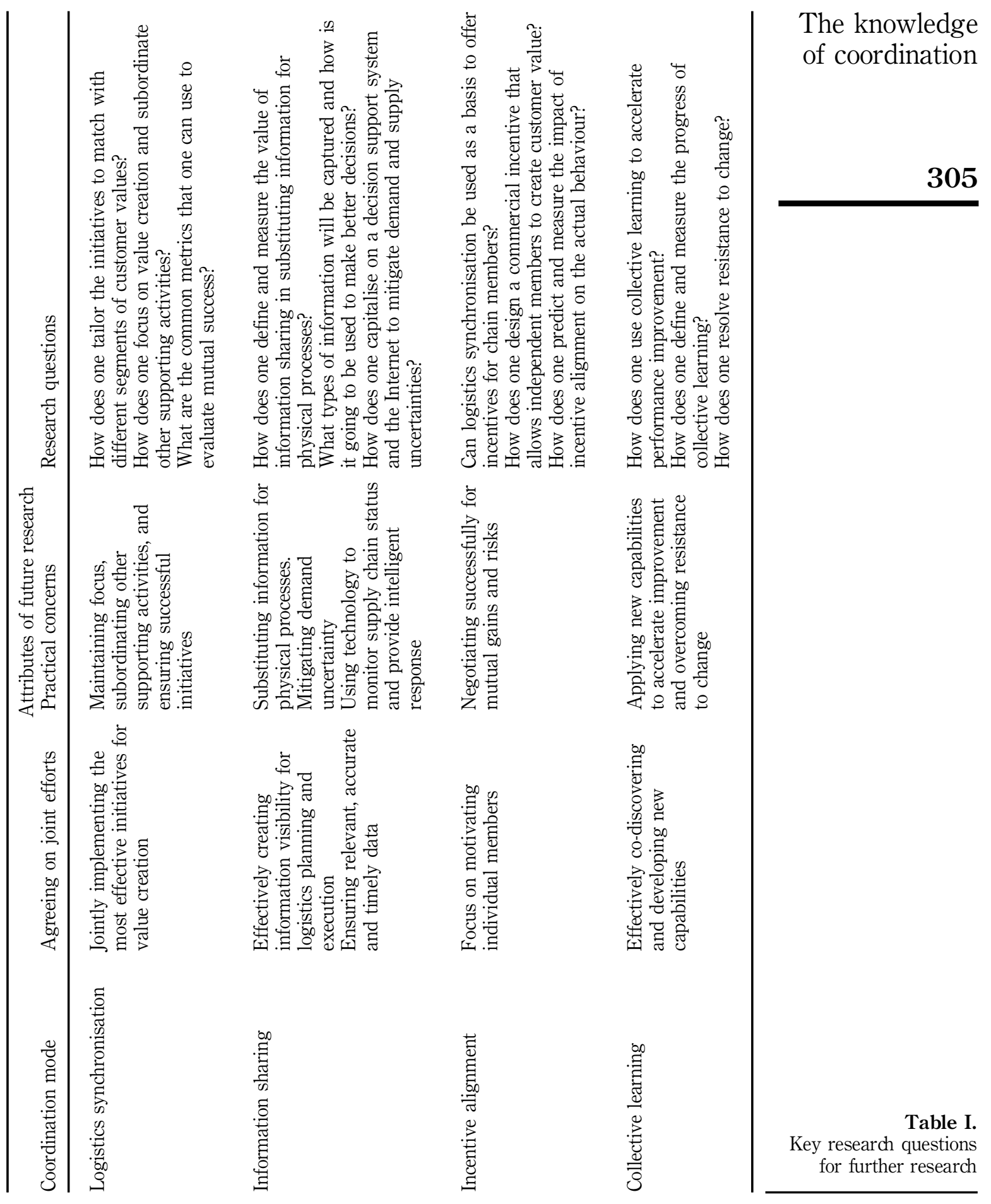


BPMJ

8,3

306

methods should be able to take advantage of scale economies and rapid response at different stages along the supply chain to compensate for risks associated with demand uncertainty and inventory obsolescence. Common metrics also need to be defined to guide the implementation process of selected initiatives on creating customer value. An important area of future research into information sharing deals with how to define and measure the real value of substituting information for physical processes (Lee and Whang, 2001). For

example, developing a mechanism to both use and share updated demand information to direct final shipments to customers provides the possibility of reducing inventory costs and mark-downs.

Incentive alignment is an active stream of research (Clemons and Row, 1993). Further research is required to properly design incentive schemes, different from those of traditional centralised planning, which need to be customised to the newly emerging kind of supply chain partnerships. For example, the computation of equitable mechanism for sharing the increase in profit or cost reduction is relatively new and needs further development (Lee $e t$ al., 1997). Moreover, logistics synchronisation requires independent partners that separately make and carry out different levels of tactical and operational decisions. Future research is needed to develop different incentive schemes that can be offered to the partners based on their performance to make and carry out decisions at specific levels. Capacity reservation, for instance, is a useful means of aligning tactical decision with the speed of delivery to replenish mid-season fashion goods. Finally, further research is required on how to use collective learning to accelerate supply chain improvement, how to define and measure the progress of collective learning, and how to overcome resistance to change. Several suggestions for measuring this progress include the learning speed (i.e. learning curve) to acquire a new capability, the intensity of capability improvement (e.g. assortment planning, demand forecasting and accurate response), and the scope of learning application (e.g. improved customer service level, reduced lead-times and lowered logistics costs).

\section{Conclusions}

Different coordination modes are required to synchronise interdependent activities, ensure visibility to match supply and demand, align actions and decision with the chain profitability, and acquire new capabilities from joint efforts. Based on dimensions of the mutuality and the focus of coordination, four modes of coordination have been identified, namely logistics synchronisation, information sharing, incentive alignment, and collective learning. The four coordination modes are simultaneously required to help participating members to advance supply chain profitability. Armed with this concept, all players will know where there is a need for matching processes, information, incentives and capabilities, so that they can carry out their valueadded tasks in support of the larger vision.

The conceptual framework of the knowledge of coordination has been presented to help practitioners and scholars understand the interplay among 
key drivers of coordination modes that have significant impact on supply chain performance. The knowledge of coordination is useful for bringing people together to inquire into the key drivers of coordination modes, identify obstacles and engage in joint problem solving. It is hoped that this article brings insights of how to fulfil the basic proposition of the supply chain initiative - namely, that the coordinated efforts provide larger benefits than the individual firm can attain alone.

\section{References}

Akkermans, H., Bogerd, P. and Vos, B. (1999), "Virtuous and vicious cycles on the road towards international supply chain management", International Journal of Operations \& Production Management, Vol. 19 Nos 5/6, pp. 565-81.

Campbell, A.J. (1997), "What affects expectations of mutuality in business relationships?", Journal of Marketing Theory and Practice, Vol. 5 No. 4, pp. 1-11.

Campbell, S. and Pereira, P. (1998), "Top two distributors get OEM parts pricing", Computer Reseller News, No. 813, 26 October, pp. 1-2.

Camuffo, A., Romano, P. and Vinelli, A. (2001), "Back to the future: Benetton transforms its global network", Sloan Management Review, Vol. 43 No. 1, pp. 46-52.

Checkland, P. (1999), Systems Thinking, Systems Practice: Includes a 30-year Retrospective, Wiley, Chichester.

Clemons, E.K. and Row, M.C. (1993), "Information, power, and control of the distribution channel", Chief Executive, Vol. 85, May, pp. 64-7.

Covington, J.W. (2000), Tough Fabric: The Domestic Apparel and Textile Chain Regain Market Share, Chesapeake Consulting, Severna Park, MD.

Dapiran, P. (1992), "Benetton - global logistics in action", International Journal of Physical Distribution \& Logistics Management, Vol. 22 No. 6, pp. 7-11.

Dyer, J.H. and Singh, H. (1998), "The relational view: cooperative strategy and sources of interorganizational competitive advantage", Academy of Management Review, Vol. 23 No. 4, pp. 660-79.

Eden, C. and Ackermann, F. (1998), Making Strategy: The Journey of Strategic Management, Saga, London.

Fisher, M.L. (1997), "What is the right supply chain for your product?", Harvard Business Review, Vol. 75 No. 2, pp. 105-16.

Goldratt, E.M. (1994), It's Not Luck, North River Press, Great Barrington, MA.

Govindarajan, V. and Gupta, A.K. (2001), "Strategic innovation: a conceptual road-map", Business Horizons, Vol. 44 No. 4, pp. 3-12.

Holweg, M. and Pil, F.K. (2001), "Successful build-to-order strategies start with the customer", Sloan Management Review, Vol. 43 No. 1, pp. 74-83.

Kogut, B. and Zander, U. (1992), "Knowledge of the firm, combinative capabilities, and the replication of technology", Organization Science, Vol. 3 No. 3, pp. 383-97.

Konijnendijk, P.A. (1994), "Coordinating marketing and manufacturing in ETO companies", International Journal of Production Economics, Vol. 37 No. 1, pp. 19-26.

Lambert, D.M., Stock, J.R. and Ellram, L.M. (1998), Fundamentals of Logistics Management, Irwin/McGraw-Hill, Boston, MA.

Lee, H.L. (2000), "Creating value through supply chain integration", Supply Chain Management Review, Vol. 4 No. 4, pp. 30-6.

The knowledge of coordination 
BPMJ

8,3

308
Lee, H.L. and Whang, S. (2001), "Winning the last mile of e-commerce", Sloan Management Review, Vol. 42 No. 4, pp. $54-62$.

Lee, H.L., Padmanabhan, V. and Whang, S. (1997), “The bullwhip effect in supply chains”, Sloan Management Review, Vol. 38 No. 3, pp. 93-102.

Lissack, M. and Roos, J. (2001), "Be coherent, not visionary”, Long Range Planning, Vol. 34 No. 1, pp. 53-70.

MacNeil, I.R. (1980), The New Social Contract, Yale University Press, New Haven, CT.

Magretta, J. (1998), "The power of virtual integration: an interview with Dell Computers' Michael Dell", Harvard Business Review, Vol. 76 No. 2, pp. 73-84.

Malone, T.W. and Crowston, K.G. (1994), "The interdisciplinary study of coordination", ACM Computing Surveys, Vol. 26 No. 1, pp. 87-119.

Milgrom, P.R. and Roberts, J. (1990), "The economics of modern manufacturing: technology, strategy, and organizations", American Economic Review, Vol. 80 No. 3, pp. 511-28.

Pyke, D., Robb, D. and Farley, J. (2000), "Manufacturing and supply chain management in China: a survey of state-, collective-, and privately-owned enterprises", European Management Joumal, Vol. 8 No. 6, pp. 577-89.

Sawhney, M. and Prandelli, E. (2000), "Communities of creation: managing distributed innovation in turbulent markets", California Management Review, Vol. 42 No. 4, pp. 24-54.

Schonfeld, E. (1998), "The customized, digitised, have-it-your-way economy", Fortune, Vol. 138 No. 6, 28 September, pp. 114-24.

Senge, P.M. (1990), The Fifth Discipline, Doubleday, New York, NY.

Simatupang, T.M. and Sridharan, R. (2002), "The collaborative supply chain: a scheme for information sharing and incentive alignment", International Journal of Logistics Management, Vol. 13 No. 2, (forthcoming).

Simchi-Levi, D., Kaminsky, P. and Simchi-Levi, E. (1999), Designing and Managing the Supply Chain, McGraw-Hill, London.

Smith, D. (2000), The Measurement Nightmare, Lucie Press, Boca Raton, FL.

Stank, T.P., Crum, M.R. and Arango, M. (1999), "Benefits of interfirm coordination in food industry supply chains", Journal of Business Logistics, Vol. 20 No. 2, pp. 21-41.

Stern, L.W., El-Anshari, A.I. and Coughlan, A.T. (1996), Marketing Channels, 5th ed., Prentice-Hall, Upper Saddle River, NJ.

Tully, S. (1993), "The modular corporation", Fortune, Vol. 127 No. 3, 8 February, pp. 106-201.

van Hoek, R.I. (2001), "The rediscovery of postponement. a literature review and directions for research", Journal of Operations Management, Vol. 19 No. 2, pp. 161-84.

Yin, R.K. (1994), Case Study Research, Sage, Thousand Oaks, CA. 